\title{
Activated Carbon and Clay Minerals for the Sorptive Removal of Denatonium Ions from Denatonium Benzoate Solutions
}

\author{
Garry S. Crosson ${ }^{1 *}$, Kenya M. Crosson ${ }^{2 *}$, Stephanie Thorpe ${ }^{1}$, Lindsie MacPherson ${ }^{2}$, \\ Madeline Murdock ${ }^{3}$, Bartina Smith ${ }^{2}$ \\ ${ }^{1}$ Department of Chemistry and Biochemistry, University of Dayton, Dayton, USA \\ ${ }^{2}$ Department of Civil and Environmental Engineering and Engineering Mechanics, University of Dayton, Dayton, \\ USA \\ ${ }^{3}$ Department of Chemical and Materials Engineering, University of Dayton, Dayton, USA \\ Email: 'gcrosson1@udayton.edu, kkcrosson1@udayton.edu
}

Received 29 July 2013; revised 25 August 2013; accepted 18 September 2013

Copyright (C) 2014 by authors and Scientific Research Publishing Inc.

This work is licensed under the Creative Commons Attribution International License (CC BY).

http://creativecommons.org/licenses/by/4.0/

(c) (i) Open Access

\section{Abstract}

This study assessed the feasibility of utilizing activated carbon and clay minerals for treating water impacted with the bittering agent denatonium benzoate (DB). Our specific study objectives were to 1) evaluate denatonium ion sorption to smectite clay minerals (bentonite and hectorite) and activated carbon (powdered and granular) at constant $\mathrm{pH}$ and ionic strength and 2) examine the impact of $\mathrm{pH}$ on denatonium ion sorption to each solid material. The experimental results indicated that high doses $(33,000 \mathrm{mg} / \mathrm{L})$ of as-received granular activated carbon and as-received clay minerals completely removed denatonium from aqueous solutions containing $100-1000$ $\mathrm{mg} / \mathrm{L}$ denatonium benzoate. Powdered activated carbon at doses of $5-100 \mathrm{mg} / \mathrm{L}$ exhibited favorable monolayer sorption of denatonium ions from a pH $6.95,70 \mathrm{mg} / \mathrm{L}$ aqueous denatonium benzoate solution with a Langmuir separation factor $(r)$ of 0.481 , a maximum sorption capacity $\left(S_{m}\right)$ of $74 \mathrm{mg} / \mathrm{g}$, and a Langmuir constant of $15.3 \mathrm{~L} / \mathrm{g}$. A maximum removal of $23 \%$ of denatonium was achieved at the highest powdered activated carbon dosage employed. Denatonium ion removal with peroxide treated bentonite and peroxide treated hectorite did not result in complete removal of the ion and exhibited favorable sorption as evidenced by Freundlich $1 / n$ values ranging from 0.803 to 1.194; Freundlich constants $\left(K_{f}\right)$ ranged from $8 \mathrm{ng} / \mathrm{L}$ to $575 \mathrm{ng} / \mathrm{L}$. Denatonium ion sorption to peroxide treated bentonite appeared to depend on $\mathrm{pH}$ while hectorite sorption of denatonium ions was independent of hydrogen ion concentrations. For powdered activated carbon adsorption, as $\mathbf{p H}$ increased denatonium ion sorption decreased. Overall, the work demonstrates that denatonium can be effectively removed from water via activated carbon or clay mineral sorption.

\footnotetext{
${ }^{*}$ Corresponding authors.
}

How to cite this paper: Crosson, G.S., Crosson, K.M., Thorpe, S., MacPherson, L., Murdock, M. and Smith, B. (2014) Activated Carbon and Clay Minerals for the Sorptive Removal of Denatonium Ions from Denatonium Benzoate Solutions. Journal of Water Resource and Protection, 6, 793-803. http://dx.doi.org/10.4236/jwarp.2014.68075 


\section{Keywords}

\section{Denatonium Benzoate, Activated Carbon, Clay Minerals, Sorption, Water Treatment, Wastewater Treatment}

\section{Introduction}

The protection of drinking water supplies from industrial and household contaminants along with the treatment of waters impacted by hazardous and undesirable constituents often involves chemical partitioning at the solid-solution interface [1]. Denatonium benzoate, shown in Figure 1, is a water soluble, bittering agent legislatively mandated to be added to antifreeze formulations in at least seventeen American states [2]; the denatonium ion is responsible for imparting the bitter taste. The principal motivation for the legislation is to prevent deaths due to accidental (or intentional) consumption of products containing ethylene glycol at concentrations exceeding $10 \% \mathrm{v} / \mathrm{v}$ [3]. As a component of antifreeze formulations, denatonium benzoate is expected to reach the soil (and possibly groundwater) through antifreeze discharges to the environment [4]. Given the large water solubility of denatonium benzoate $\left(42,400 \mathrm{mg} / \mathrm{L}\right.$ at $\left.20^{\circ} \mathrm{C}\right)$, irreversible sorption to soils and sediments may not occur resulting in denatonium benzoate seepage into ground waters or runoff into surface waters used as sources for drinking water treatment facilities. As highlighted in a meeting before a congressional subcommittee considering federal legislation mandating the addition of denatonium benzoate to antifreeze formulations, a dearth of knowledge exists related to 1 ) the environmental fate of denatonium benzoate and 2) the feasibility of current water and wastewater treatment practices for removing denatonium benzoate from impacted waters [5].

The environmental fate of quaternary ammonium compounds (QACs), such as denatonium benzoate, has been studied with the principal focus being surfactant molecules [6]-[9]. To date, data overwhelmingly support a cation exchange mechanism for sorption to pure aluminosilicate minerals and to sediments containing layered aluminosilicates [7]. The majority of aluminosilicate sorption results from a partitioning of QAC molecules between the aqueous phase and interlayer surface(s) of 2:1 layered aluminosilicates whereby exchangeable, inorganic cations are displaced in a manner related to their hydration enthalpy [10].

Several physical, chemical, and biological methods exist for treating water (and wastewater) streams. Common treatment protocols include solvent extraction, ion-exchange, precipitation, biodegradation, and adsorption. Adsorption of dissolved species usually involves activated carbon [11] and/or layered aluminosilicate sorbents [12]. Activated carbon is a common solid sorbent used to remove odorous compounds (e.g. vanillin, methylnaphthalenes, 2-pyrrolidone, 2-methylisoborneol) [13], explosive compounds such as 1,3,5-trinitro-1,3,5-triazacyclohexane (RDX) and 1,3,5,7-tetranitro-1,3,5,7-tetrazocane (HMX) [11], arsenic [14] and quaternary ammonium surfactants [15] [16] from impacted water and wastewater at treatment plants. Additionally, activated carbon was recently used in-situ to treat aquatic sediments containing hydrophobic organic compounds [17] [18].

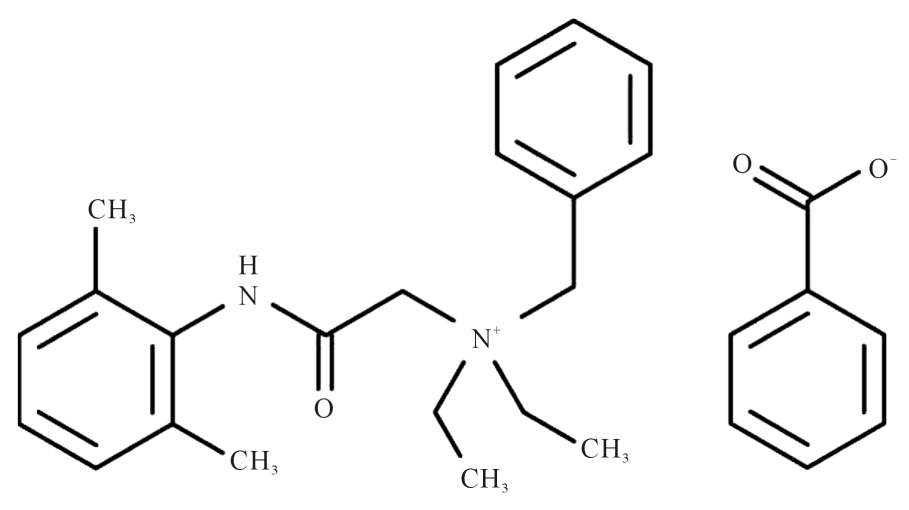

Figure 1. The structure of denatonium benzoate with the quaternary ammonium denatoniumcation and the benzoate anion. 
Despite undergoing activated carbon treatment at some wastewater treatment plants (WWTP), estuarine sediments still contained detectable levels of QACs [19] [20]. Additionally, alkyl dimethylbenzylammonium chloride and alkyltrimethylammonium chloride QACs were detected in water streams downstream of WWTPs. The detected QACs can be grouped into three classes: dialkyldimethylammonium compounds, benzylalkylammonium compounds, and alkyltrimethylammonium compounds. Generally, extremely hydrophobic compounds within the dialkyldimethylammonium class were detected in large quantities relative to less hydrophobic and less persistent compounds within the same class and in the benzylalkylammonium and alkyltrimethylammonium classes. This observation suggests that super hydrophobic compounds are not extremely biodegradable as biodegradation is extensively employed at many WWTPs [19]. Collectively, these observations highlight the need to experimentally evaluate the efficacy of using traditional sorbents (i.e. activated carbon or clay minerals) to remove aqueous denatonium benzoate (DB) prior to DB's widespread use and likely introduction into water and wastewater. Recently, our team evaluated the kinetics of denatonium ion sorption to smectite minerals and determined that 1) sorption was rapid (and near complete) when using 200 ppm initial concentrations of DB and 2) sorption likely proceeded via a cation exchange process [21].

In this work, we studied the constant temperature sorption of denatonium ions to common sorbents utilized in water treatment processes (i.e. bentonite clay and activated carbon). The study objectives are to: 1 ) evaluate denatonium ion sorption to smectites and granular activated carbon at constant $\mathrm{pH}$ and ionic strength and 2) examine the impact of $\mathrm{pH}$ on denatonium ion sorption to each solid material.

\section{Experimental}

\subsection{Materials}

Denatonium benzoate was obtained from MP Biomedicals (USA) and used without further purification. The mineral sorbents were hectorite (SHCa-1) and bentonite (SWy-2). Each mineral was obtained from the Clay Minerals Society. The reported compositions of hectorite and bentonite clay minerals are shown in Table 1.

Granular activated carbon (GAC) produced via steam activation of bituminous coal and acid washing was obtained from NORIT Company ${ }^{\circledR}$ in virgin form with grain sizes between 0.4 and $1.68 \mathrm{~mm}$. The carbon had a reported (BET) surface area of $1175 \mathrm{~m}^{2} / \mathrm{g}$, apparent density of $480 \mathrm{~g} / \mathrm{L}$, and moisture content of $2 \%$. The reported GAC pore volume distribution is $0.35 \mathrm{~cm}^{3} / \mathrm{g}, 0.22 \mathrm{~cm}^{3} / \mathrm{g}$, and $0.26 \mathrm{~cm}^{3} / \mathrm{g}$ for micropore, mesopore, and macropore volumes, respectively. This commercially manufactured carbon is widely used in chemical, food, pharmaceutical, and water applications to remove impurities. Sorption experiments used as-received activated carbon in granular form and activated carbon in powdered form. To obtain powdered activated carbon (PAC), as-received GAC was ground and sieved using a no. 325 mesh sieve to obtain $<0.045 \mathrm{~mm}$ sized particles. The PAC was then rinsed with ultrapure water and oven-dried for 30 minutes at $100^{\circ} \mathrm{C}$ prior to use. A $1500 \mathrm{mg} / \mathrm{L}$ PAC carbon slurry was prepared in ultrapure water for use in experiments. Phosphoric acid and HPLC-grade acetonitrile was purchased from Fisher Scientific and used as received.

\begin{tabular}{ccc|}
\hline Table 1. Composition of clay minerals. & \\
\hline Composition & Hectorite & Bentonite \\
\hline $\mathrm{SiO}_{2}$ & $46.66 \%$ & $61.46 \%$ \\
$\mathrm{Al}_{2} \mathrm{O}_{3}$ & $0.86 \%$ & $22.05 \%$ \\
$\mathrm{TiO}_{2}$ & $0.04 \%$ & $0.09 \%$ \\
$\mathrm{Fe}_{2} \mathrm{O}_{3}$ & $0.32 \%$ & $4.37 \%$ \\
$\mathrm{MgO}^{\mathrm{CaO}}$ & $22.05 \%$ & $2.94 \%$ \\
$\mathrm{Na}_{2} \mathrm{O}$ & $1.18 \%$ & $14.01 \%$ \\
$\mathrm{~K}_{2} \mathrm{O}$ & $1.35 \%$ & $1.47 \%$ \\
$\mathrm{LOI}: 550^{\circ} \mathrm{C}-1000^{\circ} \mathrm{C}$ & $0.14 \%$ & $0.20 \%$ \\
\hline & $5.15 \%$ & $15.47 \%$ \\
\hline
\end{tabular}




\subsection{Sorption Experiments}

Constant sorbent batch sorption tests with clay minerals (in an as-received form and in a peroxide-treated form) utilized initial denatonium benzoate concentrations ranging from $100 \mathrm{mg} / \mathrm{L}$ to $1000 \mathrm{mg} / \mathrm{L}$ in $10 \mathrm{mM} \mathrm{CaCl}$ and were completed in duplicate. All suspensions were prepared by suspending approximately $0.99 \mathrm{~g}$ clay in $30 \mathrm{~mL}$ aqueous denatonium benzoate $(0.033 \mathrm{~g} / \mathrm{mL})$ in 50 -mL polypropylene conical centrifuge tubes. Prior to each experiment, the clay and denatonium benzoate were mechanically dispersed in background electrolyte by vortexing for at least fifteen seconds. The sorbate and sorbent were mixed end-over-end for 24 hours at 25 revolutions per minute (RPM) in a temperature stabilized hybridization oven (Boekel Scientific, Feasterville, PA). The aqueous concentration of denatonium ions remaining in solution was determined via high-performance liquid chromatography (described below) after collecting 2-mL aliquots from tubes centrifuged for $30 \mathrm{~min}$ at $4150 \mathrm{~g}$.

Constant adsorbent batch sorption tests with GAC were also conducted in triplicate to evaluate the sorption of denatonium ions. GAC doses in each sample were $0.033 \mathrm{~g} / \mathrm{mL}(0.8 \mathrm{~g} / 24 \mathrm{~mL})$. A DB stock solution was prepared by mixing 0.2 grams of solid crushed $\mathrm{DB}$ into an Erlenmeyer flask filled with $100 \mathrm{~mL}$ of ultrapure, organic-free Millipore $^{\mathrm{TM}}$ water. Denatonium benzoate doses of 100 to $1000 \mathrm{mg} / \mathrm{L}$ were tested. A control experiment was run for each test to ensure that DB losses from solution resulted exclusively via sorption to activated carbon. Amber vials containing the appropriate DB concentrations and activated carbon doses were placed onto a Boekel rotary shaker (Boekel Scientific, Feasterville, PA) for continuous mixing at $25^{\circ} \mathrm{C}$ at a speed of $60 \mathrm{rpm}$ for 24 hours. Following mixing, sample aliquots were collected in syringes and filtered with Millipore Millex $0.22 \mu \mathrm{m}$ syringe filters (Bedford, MA) to filter out any remaining activated carbon. All glassware used in experiments was thoroughly washed with Versa-Clean liquid concentrated soap and placed in a bath of $10 \% \mathrm{HCl}$ for acid-washing after each use. The aqueous concentration of denatonium ions remaining in solution was determined via HPLC as was the case for sorption experiments which used clay mineral sorbents.

Constant adsorbate experiments were conducted with PAC doses ranging from 5 - $100 \mathrm{mg} / \mathrm{L}$ and initial DB concentrations of 5 or $70 \mathrm{mg} / \mathrm{L}$. These tests were conducted for 3 hours or 24 hours, but the remaining experimental protocol (mixing speed and method, number of replicates, filtering, glassware cleaning, etc.) was the same as reported for the granular activated carbon experiments.

\subsection{Chemical Analysis}

Aqueous denatonium ion concentrations were determined via high-performance liquid chromatography (HPLC) (Perkin Elmer, Series 275 HRes UV/VIS Liquid Chromatography System with autosampler) equipped with a C-18 analytical column (LiChrospher, $100 \times 4.6,5 \mu \mathrm{m}$ ) and a photo-diode array detector. Denatonium ions were colorimetrically detected at $205 \mathrm{~nm}$ in an acetonitrile-phosphoric acid (prepared with Milli-Q water) mobile phase. The column flow rate was $1.0 \mathrm{~mL} \cdot \mathrm{min}^{-1}$ with a sample analysis time of 25 minutes. The HPLC column was equilibrated prior to each measurement by maintaining a mixture composition of $60 \%$ phosphoric acid $/ 40 \%$ acetonitrile for 5 min prior to sample injection. Following each $50 \mu$ sample injection, the mixture composition was held at $60 \%$ phosphoric acid/40\% acetonitrile for 8 minutes and then linearly ramped over 2 minutes to $100 \%$ acetonitrile and held for 10 minutes. The DB retention time was $6.2 \mathrm{~min}$ in standards but varied from 6.4 - 7.1 min in supernatant solutions suggesting that dissolved solutes from the clay mineral might be present. Sorbed concentrations were determined via mass balance. Control samples consisted of denatonium benzoate solutions in centrifuge tubes or amber vials absent solid sorbents; an analysis of a control sample containing the lowest concentration of denatonium benzoate did not show detectable changes in the initial concentration suggesting that sorption to centrifuge walls, glassware, or syringe filters was not a factor. Blank samples consisting of each solid sorbent dispersed in background electrolyte were run with each experiment, and analyses of supernatant solutions for each control did not show any detectable amount of denatonium ions.

\subsection{Data Analysis}

Frequently, the partitioning of a chemical between the aqueous and solid phases is constant such that linear sorption isotherms result, and many isotherm models exist for assessing sorption data. The Freundlich model is an empirical model used to evaluate sorption onto heterogeneous surfaces and multilayer sorption onto environmental surfaces while the Langmuir model is useful for evaluating monolayer sorption processes and estimating the monolayer sorption capacity. In this work, we attempted to model all sorption data with the Freun- 
dlich and Langmuir models. The linearized Freundlich model is

$$
\log S=\log K_{f}+1 / n \log C
$$

where $S$ has units of $\mu \mathrm{g} / \mathrm{g}, K_{f}$ is the Freundlich constant $\left.(\mu \mathrm{g} / \mathrm{L})^{1-1 / n}\right), 1 / n$ is a dimensionless value which provides information on sorption favorability, and $C(\mu \mathrm{g} / \mathrm{l})$ which represents the aqueous equilibrium concentration of denatonium ions. Generally, $1 / n$ values less than unity are interpreted as reflecting a favorable sorption process while values in excess of 2 imply an unfavorable sorption process [22]. The linearized Langmuir model's four types are:

$$
\begin{aligned}
& \text { Type 1: } \frac{C}{S}=\frac{1}{S_{m}} C+\frac{1}{K_{L} S_{m}} \\
& \text { Type 2: } \frac{1}{S}=\left(\frac{1}{K_{L} S_{m}}\right) \frac{1}{C}+\frac{1}{S_{m}} \\
& \text { Type 3: } S=S_{m}-\left(\frac{1}{K_{L}}\right) \frac{S}{C} \\
& \text { Type 4: } \frac{S}{C}=K_{L} S_{m}-K_{L} S
\end{aligned}
$$

where $S$ is mass loading $(\mathrm{mg} / \mathrm{g}), C$ is the aqueous equilibrium concentration of denatonium benzoate $(\mathrm{mg} / \mathrm{L}), S_{m}$ is maximum adsorbate amount per unit weight of adsorbent when surface sites are saturated (mg/g), and $K_{L}$ is the Langmuir adsorption constant related to the affinity of binding sites $(\mathrm{L} / \mathrm{g})$.

Isotherm parameters were calculated from linear trendline equations fit to experimental data and are reported when appropriate. Correlation coefficients ( $\mathrm{R}^{2}$ values) for these linear trendlines were reported as necessary to describe an isotherm model's ability to accurately describe the experimental data. For the Langmuir isotherm, a dimensionless constant separation factor or equilibrium parameter, $r$, was also calculated using the following equation [23]:

$$
r=\frac{1}{1+K_{L} C_{o}}
$$

where $C_{o}$ is the initial concentration of denatonium benzoate $(\mathrm{mg} / \mathrm{L})$. This factor numerically expresses the Langmuir isotherm shape or key features and thereby predicts the favorability of an adsorption process as described in Table 2.

Percent removal of denatonium ions from solution was also calculated to quantify activated carbon sorption of the cation. The percent removal was determined using the following equation:

$$
\% \text { DBremoval }=\left[\left(C_{0}-C\right) / C_{0}\right] \times 100 \%
$$

\section{Results}

Figure 2 shows the impact of powdered activated carbon dose on sorption from $70 \mathrm{mg} / \mathrm{L}$ aqueous solutions of denatonium benzoate at $\mathrm{pH} 6.95$ for a 3-hour contact time. Generally, the data indicate that denatonium ion removal from solution is proportional to the powdered activated carbon dose. After 3 hours of continuous contact

Table 2. Definition of $r$-factors used to characterize sorption processes based on isotherm shape.

\begin{tabular}{cc}
\hline$r$-Value & Isotherm Type/Description of Adsorption Process \\
\hline$r>1$ & Unfavorable \\
$r=1$ & Linear \\
$0<r<1$ & Favorable \\
$r=0$ & Irreversible \\
\hline
\end{tabular}


between PAC and aqueous denatonium benzoate, a 27\% percent decrease in denatonium ion concentration was observed at the highest PAC dose utilized, while decreases of $16 \%$ and $23 \%$ occurred for $50 \mathrm{mg} / \mathrm{L}$ and $75 \mathrm{mg} / \mathrm{L}$ PAC doses, respectively. When granular activated carbon was used at a much higher dose (33,000 mg/L), 100\% removal of denatonium ions was achieved when initial denatonium benzoate concentrations of 100 to 1000 $\mathrm{mg} / \mathrm{L}$ were employed (data not shown). Given the variable aqueous conditions of treatment plant influents, the $\mathrm{pH}$-dependent removal of denatonium ions via powdered activated carbon at $5 \mathrm{mg} / \mathrm{L}$ initial DB concentrations and $20 \mathrm{mg} / \mathrm{L}$ PAC dosages was investigated as shown in Figure 3. As pH increased from 7 to 10, the percent removal of denatonium ions decreased from $93 \%$ to $72 \%$, respectively.

The Freundlich and Langmuir (Types 1 - 4) isotherm models were used to model denatonium ion sorption to powdered activated carbon from $70 \mathrm{mg} / \mathrm{L}$ denatonium benzoate solutions at $25^{\circ} \mathrm{C}$ at a 3-hour contact time. Figure 4 shows the linearized Langmuir Type 3 model's fit with the experimental data. The Type 3 Langmuir model yielded the best fit $\left(\mathrm{R}^{2}=0.9976\right)$ of the isotherm models evaluated based on a comparison of correlation coefficients ( $\mathrm{R}^{2}$ values), and the calculated isotherm parameters were as follows: $S_{m}$ equals $\mathrm{mg} / \mathrm{g}$ and $K_{L}$ equals $0.0153 \mathrm{~L} / \mathrm{g}$. For our data, the Langmuir separation factor r-value was 0.481 suggesting that the adsorption of denatonium benzoate onto the powdered activated carbon was favorable (see Table 2). The linearized Freundlich isotherm model yielded a weak correlation coefficient $\left(\mathrm{R}^{2}\right)$ of 0.69 , indicating that the data were not welldescribed by the Freundlich model.

The removal of denatonium ions from a $200 \mathrm{mg} / \mathrm{L}$ solution of denatonium benzoate in $10 \mathrm{mM}$ calcium chloride at $\mathrm{pH} 4$ to 10 using as-received bentonite and hectorite resulted in $100 \%$ removal (data not shown). Organic

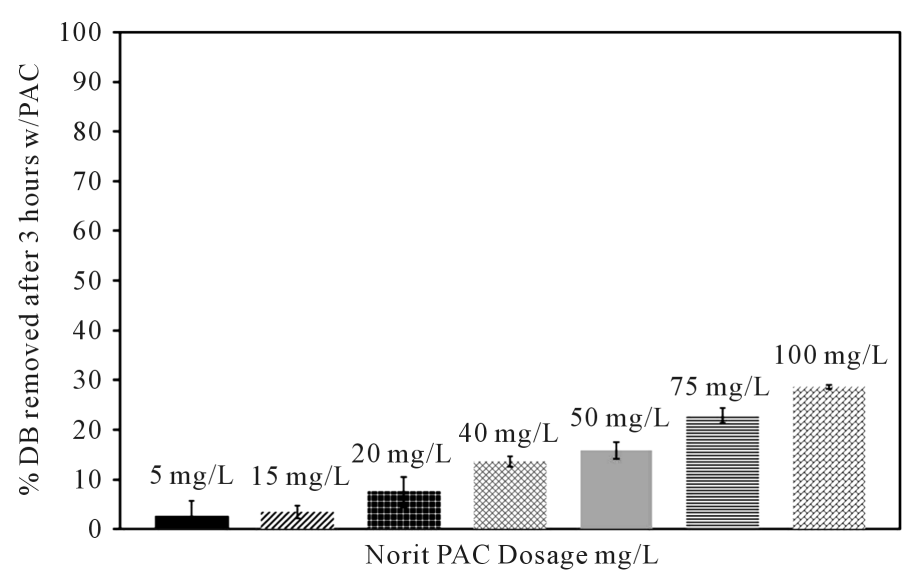

Figure 2. Norit PAC dosage impact on denatonium benzoate (DB) removal from ultrapure water $\left([\mathrm{DB}]_{\text {initial }}=70 \mathrm{mg} / \mathrm{L}, \mathrm{pH} 6.95\right)$.

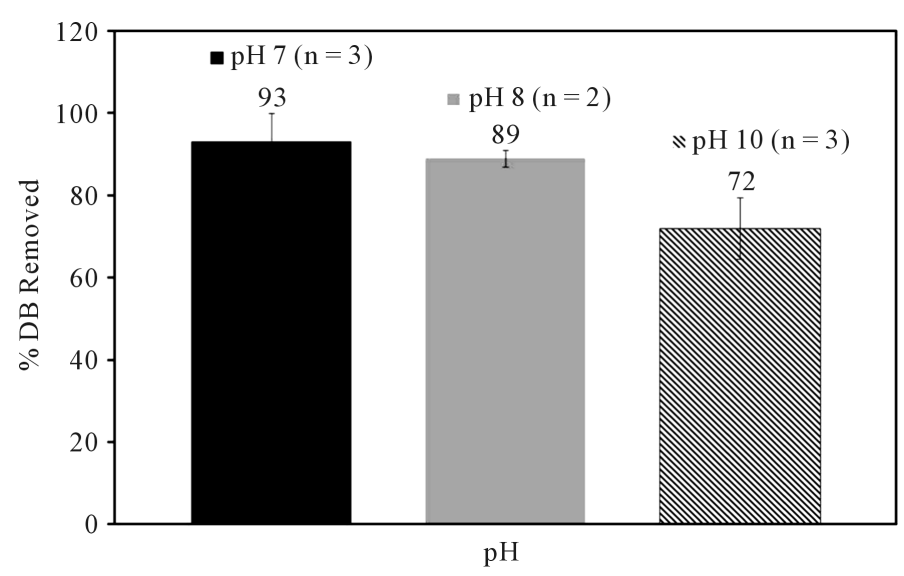

Figure 3. Impact of $\mathrm{pH}$ on aqueous denatonium benzoate (DB) sorption using powdered activated carbon $\left([\mathrm{DB}]_{\text {initial }}=5 \mathrm{mg} / \mathrm{L},[\mathrm{PAC}]_{\text {initial }}\right.$ $=20 \mathrm{mg} / \mathrm{L}$ ). 


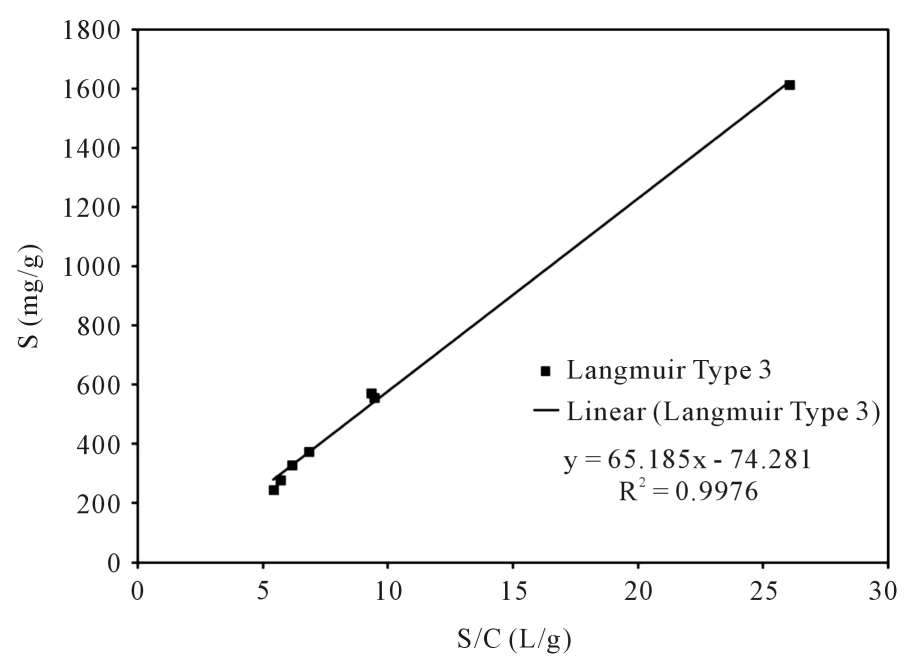

Figure 4. Langmuir isotherm of denatonium sorption by powdered activated carbon at $[\mathrm{DB}]_{\text {initial }}=70 \mathrm{mg} / \mathrm{L}$ at $\mathrm{pH}=6.95$ for at a 3-hour contact time.

matter, known to be present on mineral surfaces and dissolved within source waters, could enhance the ability of clay minerals to sequester dissolved aqueous denatonium ions. To eliminate organic matter facilitated sorption of denatonium ions, clay minerals treated with hydrogen peroxide were used as sorbents and are referred to as p-hectorite (peroxide treated hectorite) and p-bentonite (peroxide treated bentonite). The concentration dependent sorption of denatonium ions to $\mathrm{p}$-hectorite and $\mathrm{p}$-bentonite at various initial $\mathrm{pH}$ values are displayed in figure 5 with Freundlich model parameters listed in Table 3.

Regarding denatonium ion sorption to p-bentonite, initial hydrogen-ion concentrations largely impacted the sorptive behavior of denatonium ions based on a visual inspection of data shown in Figure 5(a); unfortunately, no clear trend is evident. The $1 / n$ values ranged from 1.194 to 0.803 while the Freundlich constant varied from $0.022 \mathrm{ug} / \mathrm{L}$ to $0.575 \mathrm{ug} / \mathrm{L}$ for denatonium sorption to p-bentonite. The sorption of denatonium by p-hectorite as a function of initial $\mathrm{pH}$ and denatonium benzoate concentration did not show a significant dependence on initial hydrogen ion concentrations as shown in Figure 5(b). However, at the lowest concentrations studied, there does appear to be a weak $\mathrm{pH}$ dependence of denatonium ion sorption to hectorite although a clear trend is not apparent. The $1 / n$ values ranged from 0.870 to 1.019 while the Freundlich constant varied from $0.870 \mathrm{ug} / \mathrm{L}$ to 1.019 ug/L for denatonium sorption to p-bentonite.

\section{Discussion}

The increased removal of denatonium ions as a function of activated carbon dosage is consistent with many studies which evaluated the utility of activated carbon removal of contaminants [24] [25]. For example, in a study of the sorptive capacity of granular activated carbon using the cationic dye methylene blue, the authors observed that sorption was directly proportional to the dosage of size-fractionated carbon [24]. Additionally, methylene blue and several other dyes exhibit Langmuir sorption characteristics similar to our observed sorption of denatonium ions onto powdered activated carbon (Figure 4) [26]-[28]. Sorption of organic molecules or ions to highsurface area sorbents can be influenced by number of solution conditions including $\mathrm{pH}$, ionic strength, temperature, nature of background electrolyte, etcetera [29] [30]. Furthermore, for large organic cations such as denatonium, electrostatic and dispersion interactions are possible given the inherent non-polar nature of the molecular ion and the ion charge [31]-[33]. Thus, one can reasonably conclude that electrostatic and dispersive interactions influenced activated carbon sorption of denatonium ions under the conditions studied since denatonium is a permanently charged cation and the activated carbon sorption sites tend to be negatively charged. Consequently, observed increases in denatonium ion sorption are likely related to an increased quantity of available cation sorption sites with increased powder activated carbon dose. The role of pore structure (size and volume) on denatonium ion adsorption is yet to be examined, but pore structure could play a key role in adsorption. The sorptive behavior of denatonium ions to peroxide treated clay minerals can be explained by considering the impact 
Table 3. Freundlich sorption parameters for p-bentonite and p-hectorite clays.

\begin{tabular}{|c|c|c|c|c|c|c|c|}
\hline \multicolumn{4}{|c|}{ p-bentonite } & \multicolumn{4}{|c|}{ p-hectorite } \\
\hline $\mathrm{pH}$ & $K_{f}(\mathrm{ug} / \mathrm{L})$ & $(1 / n)$ & $\mathrm{R}^{2}$ & $\mathrm{pH}$ & $K_{f}(\mathrm{ug} / \mathrm{L})$ & $(1 / n)$ & $\mathrm{R}^{2}$ \\
\hline 4 & 0.022 & 1.194 & 0.994 & 4 & 0.106 & 0.870 & 0.979 \\
\hline 6.5 & 0.478 & 0.934 & 0.993 & 7 & 0.008 & 1.086 & 0.996 \\
\hline 8.5 & 0.007 & 1.113 & 0.999 & 8 & 0.034 & 0.962 & 0.999 \\
\hline 10 & 0.575 & 0.803 & 0.983 & 10 & 0.019 & 1.019 & 0.995 \\
\hline
\end{tabular}

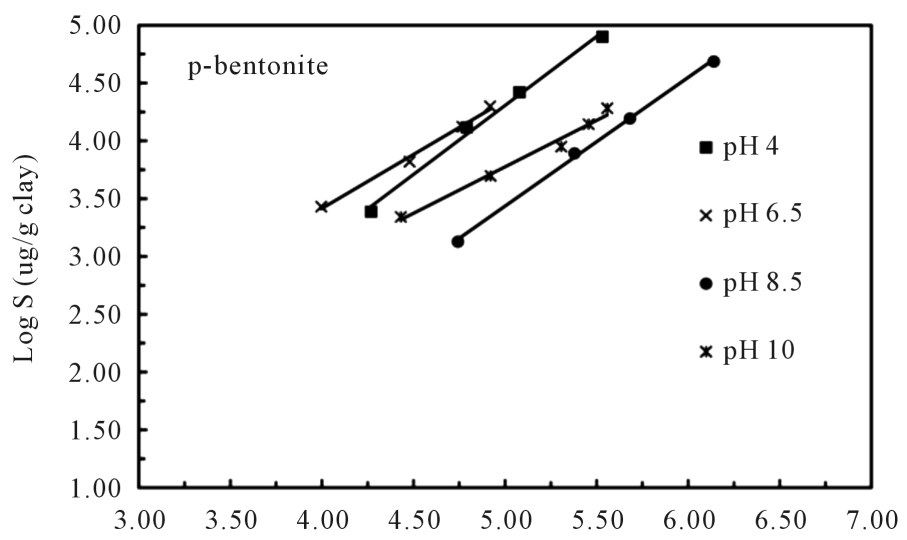

(a)

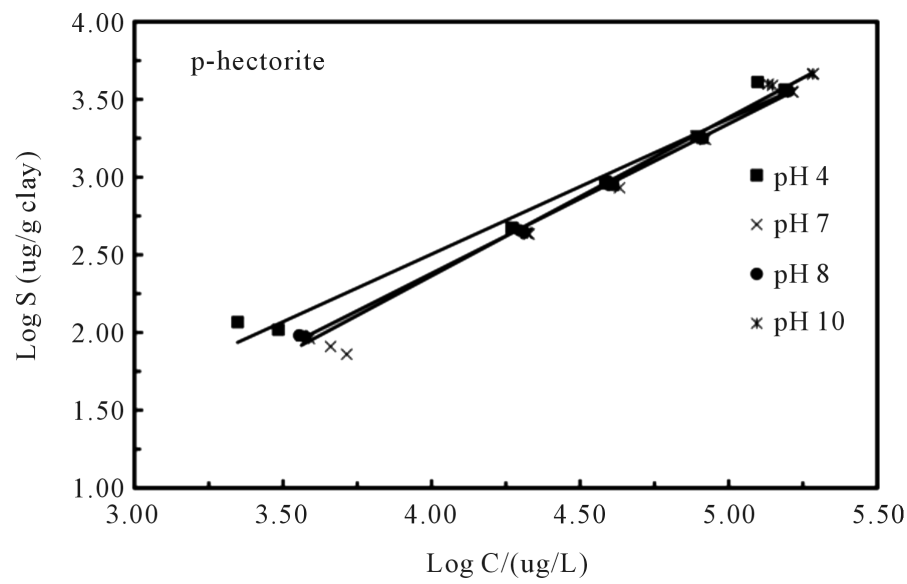

(b)

Figure 5. Freundlick sorption isotherms of denatonium sorption by (a) p-bentonite and (b) p-hectorite in $10 \mathrm{mM} \mathrm{CaCl}_{2}$ at the indicated $\mathrm{pH}$ values.

of peroxide on the clay composition. Peroxide treatment is a well-established method for reducing the organic matter content [34]. Loss-on-ignition data listed in Table 1 for the bentonite and hectorite clay minerals indicate $5.47 \%$ and $15.15 \%$, respectively, by mass of organic carbon. In our study, the observed decrease in sorption affinity of denatonium ions for bentonite and hectorite clay minerals following peroxide treatment suggests that clay mineral sorption sites and sorption domains within organic matter contribute to the attenuation of denatonium ions. Enhanced sorption of large molecular weight organic cations to mineral surfaces is not unique to our study and has been attributed to enhanced van der Waals interactions between the solute and organic matter in some cases and electrostatic interactions between charged solutes and deprotonated acids in organic matter which can vary with $\mathrm{pH}$ [35]. 
The observation of $\mathrm{pH}$-independent sorption of denatonium ions to p-hectorite coupled with pH-dependent sorption to p-bentonite suggests that sorption does not exclusively occur at the same type of sorption site. Smectite minerals are known to possess internal $\mathrm{pH}$-independent cation sorption sites and external $\mathrm{pH}$-dependent sorption sites. Thus, we conclude that internal cation-exchange sorption sites within p-hectorite are most likely responsible for reduced aqueous denatonium ion concentrations although sorption to external, $\mathrm{pH}$-independent sites cannot be ruled out. Others have observed quaternary ammonium cation sorption to hectorite and concluded that the process likely involved interlayer exchanges of cations [36]. In the case of p-bentonite, a plausible explanation for the observed $\mathrm{pH}$-dependent sorption is that both internal and external sorption sites contributed to the attenuation of denatonium ions. Given the interlayer accessibility of denatonium ions, sorption to internal sites is expected, however the relative number of external sites versus internal sites could favor $\mathrm{pH}$-dependent sorption resulting in hydrogen-ion concentration dependent isotherms. Since $1 / n$ values generally fell between 0.803 and 1.194, the sorption of denatonium ions to each clay mineral could be classified as moderate to highly favorable under the conditions of our study [22].

\section{Conclusion}

The removal of aqueous denatonium ions from water by common solid sorbents used in water treatment processes was studied. Generally, denatonium ion concentrations are significantly decreased when smectite or activated carbon sorbents are utilized. In the case of smectite removal, multiple sorption sites were inferred whereby sorption occurred to $\mathrm{pH}$-independent sorption sites within the interlayer and $\mathrm{pH}$-dependent sites on the external clay surface. Peroxide treated clay minerals showed decreased sorption relative to as-received minerals from which we conclude that oxidized organic matter facilitated denatonium ion sorption. The efficiency of activated carbon removal of denatonium ions increases with decreasing $\mathrm{pH}$ and increasing activated carbon dosage which suggest that electrostatics and increased sorption site availability impact denatonium ion sorption. Thus, the use of clay mineral sorbents or activated carbon for the removal of denatonium ions from solution by treatment facilities is expected to be feasible and of great utility under various environmental conditions.

\section{Acknowledgements}

K.M.C gratefully acknowledges financial support from the Ohio Water Development Authority through grant 5764. G.S.C. acknowledges funding for equipment and personnel from the United States Geological Survey, State Water Resources Research Institute Program of Ohio through grant 2010OH169B. The Department of Chemistry and Biochemistry provided additional support for this work through in-kind equipment provided to K.M.C. The University of Dayton Sustainability, Energy and Environment (SEE) program provided support to G.S.C and K.M.C. K.M.C and G.S.C also recognize The University of Dayton Research Institute SEED grant program and Research Fellows for materials support.

\section{References}

[1] Sparks, D.L. (1995) Environmental Soil Chemistry. 4th Edition, Academic Press, San Diego.

[2] Association, C.S.P. (2013) Making Antifreeze and Engine Coolant Unpalatable to Humans and Animals.

[3] Henderson, M.C., Neumann, C.M. and Buhler, D.R. (1998) Analysis of Denatonium Benzoate in Oregon Consumer Products by HPLC. Chemosphere, 36, 203-210. http://dx.doi.org/10.1016/S0045-6535(97)10033-9

[4] Reddy, C.M. and Quinn, J.G. (1997) Environmental Chemistry of Benzothiazoles Derived from Rubber. Environmental Science \& Technology, 31, 2847-2853. http://dx.doi.org/10.1021/es970078o

[5] H.R. 2567 (2006) The Antifreeze Bittering Act of 2005. Energy and Commerce, 2nd Edition, Government Printing Office, Washington DC, 155.

[6] Brownawell, B.J., Chen, H., Collier, J.M. and Westall, J.C. (1990) Adsorption of Organic Cations to Natural Materials. Environmental Science \& Technology, 24, 1234-1241. http://dx.doi.org/10.1021/es00078a011

[7] Zhang, Z.Z., Sparks, D.L. and Scrivner, N.C. (1993) Sorption and Desorption of Quaternary Amine Cations on Clays. Environmental Science \& Technology, 27, 1625-1631. http://dx.doi.org/10.1021/es00045a020

[8] Boyd, S.A., Mortland, M.M. and Chiou, C.T. (1988) Sorption Characteristics of Organic-Compounds on Hexadecyltrimethylammonium-Smectite. Soil Science Society of America Journal, 52, 652-657. http://dx.doi.org/10.2136/sssaj1988.03615995005200030010x 
[9] Xu, S. and Boyd, S.A. (1995) Alternative Model for Cationic Surfactant Adsorption by Layer Silicates. Environmental Science \& Technology, 29, 3022-3028. http://dx.doi.org/10.1021/es00012a020

[10] Wang, C., Ding, Y., Teppen, B.J., Boyd, S.A., Song, C. and Li, H. (2009) Role of Interlayer Hydration in Lincomycin Sorption by Smectite Clays. Environmental Science \& Technology, 43, 6171-6176. http://dx.doi.org/10.1021/es900760m

[11] Parette, R., Cannon, F.S. and Weeks, K. (2005) Removing Low Ppb Level Perchlorate, RDX, and HMX from Groundwater with Cetyltrimethylammonium Chloride (CTAC) Pre-Loaded Activated Carbon. Water Research, 39, 4683-4692. http://dx.doi.org/10.1016/j.watres.2005.09.014

[12] De Oliveira, M.F., Johnston, C.T., Premachandra, G.S., Teppen, B.J., Li, H., Laird, D.A., Zhu, D.Q. and Boyd, S.A. (2005) Spectroscopic Study of Carbaryl Sorption on Smectite from Aqueous Suspension. Environmental Science \& Technology, 39, 9123-9129. http://dx.doi.org/10.1021/es048108s

[13] Agus, E., Lim, M.H., Zhang, L. and Sedlak, D.L. (2011) Odorous Compounds in Municipal Wastewater Effluent and Potable Water Reuse Systems. Environmental Science \& Technology, 45, 9347-9355. http://dx.doi.org/10.1021/es202594z

[14] Chen, W.F., Parette, R. and Cannon, F.S. (2012) Pilot-Scale Studies of Arsenic Removal with Granular Activated Carbon and Zero-Valent Iron. Environmental Engineering Science, 29, 897-901. http://dx.doi.org/10.1089/ees.2011.0386

[15] Basar, C.A., Karagunduz, A., Cakici, A. and Keskinler, B. (2004) Removal of Surfactants by Powdered Activated Carbon and Microfiltration. Water Research, 38, 2117-2124. http://dx.doi.org/10.1016/j.watres.2004.02.001

[16] Adachi, A., Kamide, M., Kawafune, R., Miki, N. and Kobayashi, T. (1990) Removal Efficiency of Anionic and Nonionic Surfactants from Chemical Waste-Water by a Treatment-Plant Using Activated Carbon Adsorption and Coagulation Precipitation Processes. Environmental Technology, 11, 133-140. http://dx.doi.org/10.1080/09593339009384847

[17] Oen, A.M.P., Beckingham, B., Ghosh, U., Kruså, M.E., Luthy, R.G., Hartnik, T., Henriksen, T. and Cornelissen, G. (2011) Sorption of Organic Compounds to Fresh and Field-Aged Activated Carbons in Soils and Sediments. Environmental Science \& Technology, 46, 810-817. http://dx.doi.org/10.1021/es202814e

[18] Kupryianchyk, D., Rakowska, M.I., Roessink, I., Reichman, E.P., Grotenhuis, J.T.C. and Koelmans, A.A. (2013) In Situ Treatment with Activated Carbon Reduces Bioaccumulation in Aquatic Food Chains. Environmental Science \& Technology, 47, 4563-4571. http://dx.doi.org/10.1021/es305265x

[19] Li, X. and Brownawell, B.J. (2010) Quaternary Ammonium Compounds in Urban Estuarine Sediment EnvironmentsA Class of Contaminants in Need of Increased Attention? Environmental Science \& Technology, 44, 7561-7568. http://dx.doi.org/10.1021/es1011669

[20] Li, X.L. and Brownawell, B.J. (2009) Analysis of Quaternary Ammonium Compounds in Estuarine Sediments by LC-ToF-MS: Very High Positive Mass Defects of Alkylamine Ions as Powerful Diagnostic Tools for Identification and Structural Elucidation. Analytical Chemistry, 81, 7926-7935. http://dx.doi.org/10.1021/ac900900y

[21] Crosson, G. and Sandmann, E. (2013) Kinetic Study of Denatonium Sorption to Smectite Clay Minerals. Environmental Engineering Science, 30, 311-316. http://dx.doi.org/10.1089/ees.2012.0308

[22] Ma, J., Yu, F., Zhou, L., Jin, L., Yang, M.X., Luan, J.S., Tang, Y.H., Fan, H.B., Yuan, Z.W. and Chen, J.H. (2012) Enhanced Adsorptive Removal of Methyl Orange and Methylene Blue from Aqueous Solution by Alkali-Activated Multiwalled Carbon Nanotubes. ACS Applied Materials \& Interfaces, 4, 5749-5760. http://dx.doi.org/10.1021/am301053m

[23] Ho, Y.S., Malarvizhi, R. and Sulochana, N. (2009) Equilibrium Isotherm Studies of Methylene Blue Adsorption onto Activated Carbon Prepared from Delonix Regia Pods. Journal of Environmental Protection Science, 3, 111-116.

[24] Raposo, F., De La Rubia, M.A. and Borja, R. (2009) Methylene Blue Number as Useful Indicator to Evaluate the Adsorptive Capacity of Granular Activated Carbon in Batch Mode: Influence of Adsorbate/Adsorbent Mass Ratio and Particle Size. Journal of Hazardous Materials, 165, 291-299. http://dx.doi.org/10.1016/j.jhazmat.2008.09.106

[25] Arslanoğlu, F.N., Kar, F. and Arslan, N. (2005) Adsorption of Dark Coloured Compounds from Peach Pulp by Using Granular Activated Carbon. Journal of Food Engineering, 68, 409-417. http://dx.doi.org/10.1016/j.jfoodeng.2004.06.017

[26] Kumar, K.V. and Sivanesan, S. (2006) Isotherm Parameters for Basic Dyes onto Activated Carbon: Comparison of Linear and Non-Linear Method. Journal of Hazardous Materials, 129, 147-150. http://dx.doi.org/10.1016/j.jhazmat.2005.08.022

[27] Mittal, A., Krishnan, L. and Gupta, V.K. (2005) Removal and Recovery of Malachite Green from Wastewater Using an Agricultural Waste Material, De-Oiled Soya. Separation and Purification Technology, 43, 125-133. http://dx.doi.org/10.1016/j.seppur.2004.10.010

[28] Itodo, A.U., Itodo, H.U. and Gafar, M.K. (2010) Estimation of Specific Surface Area Using Langmuir Isotherm Method. Journal of Applied Science and Environmental Management, 14, 141-145. 
[29] Li, H., Teppen, B.J., Laird, D.A., Johnston, C.T. and Boyd, S.A. (2004) Geochemical Modulation of Pesticide Sorption on Smectite Clay. Environmental Science \& Technology, 38, 5393-5399. http://dx.doi.org/10.1021/es0494555

[30] Li, H., Teppen, B.J., Laird, D.A., Johnston, C.T. and Boyd, S.A. (2006) Effects of Increasing Potassium Chloride and Calcium Chloride Ionic Strength on Pesticide Sorption by Potassium- and Calcium-Smectite. Soil Science Society of America Journal, 70, 1889-1895. http://dx.doi.org/10.2136/sssaj2005.0392

[31] Hower, W.F. (1970) Adsorption of Surfactants on Montmorillonite. Clays and Clay Minerals, 18, 97-105. http://dx.doi.org/10.1346/CCMN.1970.0180205

[32] Bohmer, M.R. and Koopal, L.K. (1992) Adsorption of Ionic Surfactants on Variable-Charge Surfaces. 1. Charge Effects and Structure of the Adsorbed Layer. Langmuir, 8, 2649-2659. http://dx.doi.org/10.1021/la00047a014

[33] Pendleton, P. and Wu, S.H. (2003) Kinetics of Dodecanoic Acid Adsorption from Caustic Solution by Activated Carbon. Journal of Colloid and Interface Science, 266, 245-250. http://dx.doi.org/10.1016/S0021-9797(03)00575-7

[34] Gao, J.P., Maguhn, J., Spitzauer, P. and Kettrup, A. (1998) Sorption of Pesticides in the Sediment of the Teufelsweiher Pond (Southern Germany). I: Equilibrium Assessments, Effect of Organic Carbon Content and pH. Water Research, 32, 1662-1672. http://dx.doi.org/10.1016/S0043-1354(97)00377-1

[35] Mermut, A.R. and Cano, A.F. (2001) Baseline Studies of The Clay Minerals Society Source Clays: Chemical Analyses of Major Elements. Clays and Clay Minerals, 49, 381-386. http://dx.doi.org/10.1346/CCMN.2001.0490504

[36] Chattopadhyay, S. and Traina, S.J. (1999) Spectroscopic Study of Sorption of Nitrogen Heterocyclic Compounds on Phyllosilicates. Langmuir, 15, 1634-1639. http://dx.doi.org/10.1021/la980607h 
Scientific Research Publishing (SCIRP) is one of the largest Open Access journal publishers. It is currently publishing more than 200 open access, online, peer-reviewed journals covering a wide range of academic disciplines. SCIRP serves the worldwide academic communities and contributes to the progress and application of science with its publication.

Other selected journals from SCIRP are listed as below. Submit your manuscript to us via either submit@scirp.org or Online Submission Portal.
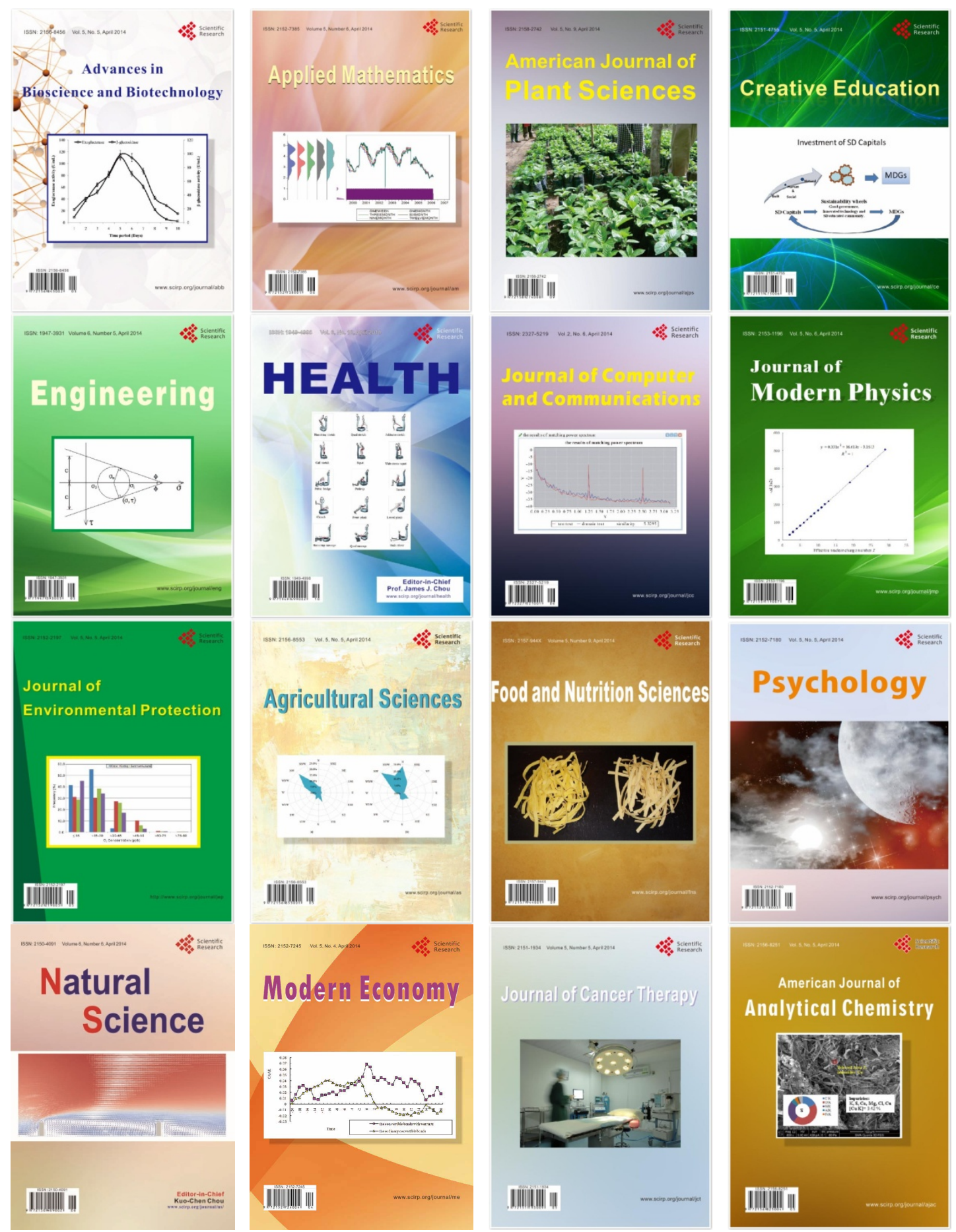